\title{
FENOMENOLOGIA DE LA EXISTENCIA SOCIAL Y EDUCACIÓN
}

\section{Carlos J. Tealdi}

\section{El carácter social de la existencia humana}

Para la fenomenología existencial el hombre es esencial y fundamentalmente "existencia", o sea, un sujeto-abierto-al mundo, un "ser-en-el-mundo" según la clásica expresión de Heidegger. Esto significa que el mundo está siempre implicado en el ser del hombre, y que por lo tanto no podemos concebir al hombre independientemente del mundo. El hombre es una presencia consciente al mundo.

Pero la presencia del hombre al mundo no es una presencia solitaria. Su presencia es una co-presencia, su existencia una coexistencia; dicho de otro modo, el hombre es un "ser-con-otros-en-elmundo".

Los términos "co-presencia", co-existencia", "ser-con" se utilizan para expresar que el hombre no está totalmente solo en ningún nivel de su existencia. Ningún aspecto del ser-hombre es lo que es si no están "presentes" en él otros seres humanos. Ser hombres es "ser-a través-delos otros". Expresado en otros términos, el hombre es un ser social en todo. Sin excluir la zona natural o biológica de nuestra existencia -en ella se podría admitir también un comportamiento social en función de las leyes de la herencia-, la afirmación se refiere esencialmente a todo aquello que en el hombre está sujeto a la responsabilidad humana, o sea, a aquella zona de nuestra existencia en la cual somos un autoproyecto, en la cual podemos aprender, ejercer un control y dar forma a nuestro propio ser. Con respecto a esta zona sostenemos que el hombre es social.

Es habitual distinguir en nuestra existencia dos esferas: una esfera personal o privada y otra social. Hay actividades que implican un contacto con nuestros semejantes, y hay actividades que desarrollamos solos. Unicamente las primeras parecerían tener un carácter social. Sin embargo, si prestamos mejor atención, comprobamos que aún las tareas 
que desarrollamos solos poseen también un carácter social. El hombre que se afeita, por ejemplo, actúa de acuerdo a una costumbre social. Usa además de un instrumento que no ha sido inventado ni fabricado por él, sino que lo ha recibido de sus semejantes. Más aún, el afeitarse es algo que él ha aprendido en su estar junto a otros hombres, sin contar que lo hace porque quiere aparecer bien presentado ante sus semejantes. Nuestras actividades son sociales, pues, no solamente porque las realizamos junto con otros, sino también porque las hemos aprendido de otros, las ejecutamos conforme a normas aceptadas, y las hacemos en vista de nuestros semejantes. Aún en el hecho de querer "estar solos" está contenida una referencia a los demás, sin contar que querer estar solos en una especie de norma social.

Podríamos objetar que al menos nuestro pensar no es un acto social, en tanto que el mismo tiene lugar necesariamenrte en nuestra interioridad. Pero debemos reconocer que aún en la reflexión personal se manifiesta lo social, puesto que la efecutamos utilizando un lenguaje que hemos aprendido de nuestros semejantes y conforma a una visión de las cosas también aprendida en nuestro trato con los demás.

Una objeción puede plantearse todavía con relación al término "social". Si la socialidad impregna la totalidad de nuestra existencia, ¿qué valor puede asignársele todavía al término "social"?. Un término que puede significarlo todo en última instancia no significa nada. Respondemos a la objeción diciendo que si bien la socialidad es un aspecto del hombre que lo penetra todo, esto no excluye otros aspectos. La existencia humana, como veremos, no sólo tiene carácter social sino también personal, libre, pero sin que esto signifique referirse a sectores distintos y separados de nuestro ser. Nuestra existencia es una existencia social, una existencia que en todo lo que somos está contenída una relación con nuestros semejantes, pero sin dejar por ello de ser al mismo tiempo una existencia personal, autónoma, que vive por sí misma y desde sí misma. Esto es lo que no ha comprendido el determinismo social o socioligismo, que pasamos a considerar.

\section{El determinismo social o sociologismo.}

Una de las características fundamentales de nuestra época consiste en el redescubrimiento del carácter social de la existencia humana. El 
hombre contemporáneo tiene una conciencia mucho más clara de esta dimensión social. Sin embargo, por cuanto el intelecto humano difícilmente puede escapar de la unilateralidad, no debe extrañarnos que el gran descubrimiento de una época sea interpretado de una manera exagerada. En los siglos próximos pasados, todo el énfasis se ponía en el poder creador de la libertad individual, y este énfasis llevó a la ideología del individualismo. En el presente, el hombre acentúa la dimensión social de su existencia. Este énfasis conduce a otra ideología: el determinismo social o sociologismo.

En efecto, para el determinismo social el hombre es sólo el producto o el resultado de estructuras y procesos sociales. Las influencias sociales determinan nuestras vidas de una manera tal que no tenemos conciencia de ella. La autonomía y la libertad son meras ilusiones.

El determinismo social, más que una teoŕa, es una doctrina implícita en toda sociología de corte positivista y, en general, en toda filosofía de carácter cientista o fisicalista. El positivismo, el marxismo, el estructuralismo, el conductismo, el neopositivismo son distitnas variantes de un mismo planteo determinista que ha influido y sigue influyendo profundamente en el campo de la educación. Tales posiciones, caracterizadas globalmente como antropologías "sin sujeto", constituyen el fundamento de las teorías pedagógicas centradas en las técnicas reproductoras con menosprecio de los aspectos individuales y creativos.

El determinismo social tendría razón si nuestros vínculos sociales implicaran la pérdida de nuestra autonomía. En efecto, si una actividad humana es llamada social, este término parece implicar que en el cumplimiento de dicha actividad somos dependientes de otros, estamos influidos por otros. De ahí a pretender que nuestra acción no procede de nosotros mismos, es decir, que no actuamos de manera autónoma, hay sólo un paso. Pues aquello que es causado por algo exterior a nosotros ya no puede proceder de nosotros. Esta línea de razonamiento, sin embargo, está signada por un pensar en la categoría de una causalidad determinística propia de las cosas. Cuando una cosa ejerce una influencia sobre otra, la influencia en cuestión significa una real y 
efectiva determinación. Si el fuego calienta el agua, ésta, para poder calentarse, depende totalmente de la influencia del fuego. Ahora bien, si comprendiéramos del mismo modo la influencia que un hombre ejerce sobre otro, entonces la autonomía de una persona implicaría realmente la negación de toda influencia por parte de los otros. El determinismo social, pues, parte de presupuesto de concebir la influencia de los otros como una influencia de carácter determinista, y en consecuencia afirma que la independencia y la libertad del hombre son ilusiones. Sin embargo, estar sujeto a influencias no significa necesariamente estar sujeto a una influencia de carácter determinista. Si escucho los argumentos de alguien y ellos me ayudan a alcanzar una comprensión del problema, entonces es cierto que he alcanzado esa comprension gracias a él, pero también es verdad que al mismo tiempo he alcanzado yo mismo tal comprensión. En nuestra existencia, pues, está contenida una relación con nuestros semejantes, relación que no podemos separar de nuestra vida, pero esta relación no es una relación de carácter determinista, ni solamente una relación de dependencia. Nuestra existencia, si bien es dependiente, conserva al mismo tiempo cierto grado de autonomía. Esto se hará más evidente analizando el concepto fenomenologico de "facticidad".

\section{La facticidad social}

La dimensión social es un dato de experiencia que puede ser observado y estudiado con métodos científicos. Las pautas de comportamiento de un pueblo, sus hábitos de vestido y de comida, su manera de comunicarse, su lenguaje, sus instituciones, todo puede ser observado y analizado como hechos dados. También su estilo de pensamiento puede ser señalado como un hecho, puesto que la manera de pensar de un grupo está estrechamente vinculada con la estructura del lenguaje hablado por ese grupo. Aún las normas que gobiernan a un pueblo, sus normas de cortesía, sus normas estéticas y sus normas morales son algo que es fácticamente dado. Ahora bien, si la dimensión social constituye realmente un hecho, puede por tanto ser estudiada como cualquier otro hecho y determinar sus leyes. Todo esto indica un nuevo campo científico. La clásica distinción entre "ciencias de la naturaleza", que 
formulan leyes necesarias, y "ciencias del espíritu", que sólo establecen normas, se ha revelado insuficiente. También en el hombre en cuanto hombre, en su vida del espiritu, existe una inmensa región de hechos, de facticidad. Por esta razón las ciencias del hombre se han convertido en ciencias positivas. El problema que aquí se enfrenta, pues, es el del "status" que ha de asignarse a las más recientes ciencias del hombre, como la sociología, la psicología, la economia y las ciencias del lenguaje, de la cultura y de la historia. Dichas ciencias se refieren a un campo de datos fácticos y se niegan a ser consideradas ciencias normativas.

Podría decirse que en la esfera del espíritu se ha descubierto una zona de naturaleza. La misma está representada por nuestros hábitos y costumbres. Los hábitos y costumbres son existencia solidificada. Asumen la forma de la naturaleza y obran en nosotros de tal manera que de ordinario ni siquiera tenemos conciencia de ellos. Los hábitos y costumbres dan una cierta fijeza al comportamiento humano. Por eso constituyen como una segunda naturaleza del hombre. Esta "segunda" naturaleza es similar en muchos aspectos a nuestra "primera" naturaleza, naturaleza tomada en el sentido ordinario o biológico del término. Ambas son algo dado, ambas pueden ser estudiadas empíricamente, ambas nos hacen esperar cosas que realmente ocurrirán. Si conocemos bien los hábitos de una persona, sabremos con bastante certeza cómo va a reaccionar. Si prestamos atención no ya a los hábitos de un individuo sino a los de toda una nación, nuestra certeza se vuelve aún mayor. La "segunda" naturaleza, pues, parece revelar la misma estabilidad y la misma regularidad que la "primera" naturaleza. En razón de esta semejanza, las ciencias del hombre han asumido el método de las ciencias naturales, dando por descontado muy a menudo que la "segunda" naturaleza estaría caracterizada por la misma necesidad que la "primera". En algunos casos, estas ciencias fueron lo suficientemente lejos como para asumir el lenguaje de las matemáticas. En este caso no hay, por supuesto, lugar para la libertad, o sea que estamos en la esfera del determinismo.

Ahora bien, a pesar de la semejanza en varios aspectos entre la "primera" y "segunda" naturaleza, y a pesar de que comúnmente no tenemos conciencia de la influencia de la "segunda" naturaleza en 
nuestro comportamiento, sin embargo debemos reconocer que esta última se ha originado en un proyecto humano, y como tal puede ser modificada por otro proyecto. Aunque los hábitos y costumbres del hombre muestren una regularidad, internamente siguen siendo contingentes y mudables. A veces cambian muy lentamente, pero también en ocasiones están sujetos a cambios rápidos, que es lo que ocurre en los tiempos actuales. Este hecho ha permitido tomar conciencia de que los métodos de las ciencias naturales no pueden ser aplicados sin ciertas restricciones al estudio y comprensión de la vida humana.

En relación con este problema aparece como muy importante el concepto fenomenologico de facticidad, que encontramos en las obras de Heidegger, Sartre, Merleau-Ponty y otros. El término "facticidad" designa la clase típicamente humana de hechos que condicionan la existencia del hombre. El que se haya acuñado un término especial muestra que esos pensadores no querían identificar sin más la "segunda" naturaleza con la "primera". La fenomenología existencial reconoce que la condición fáctica del hombre tiene un carácter "sui géneris". La facticidad es algo dado, que tiene su propia densidad y que no está sujeta a la arbitrariedad del espíritu libre. Es una orientación determinada de la existencia, y presenta líneas fijas que pueden ser establecidas de una manera empírica. Un claro ejemplo de ello es el lenguaje. El lenguaje presenta una estructura fija que no puede ser dejada de lado por el hombre en su hablar. La estructura de un lenguaje es un fenómeno social y trasciende la arbitrariedad del individuo. Las reglas de un lenguaje pueden ser establecidas, y lo mismo puede hacerse con las que corresponden a su desarrollo histórico. La facticidad, por tanto, presenta un carácter cósico, y en cierta medida puede ser tratada de la misma manera que una cosa. Sin embargo no puede ser tratada incondicionalmente como una cosa. La razón de ello es que en la facticidad está presente la intencionalidad de la existencia. La intencionalidad es una búsqueda de sentido, de significado. La facticidad se ha originado en una existencia intencional; por tanto, es desde dentro un significado para dicha existencia. El lenguaje no es sólo una realidad fáctica cuyo desarrollo se rige por leyes más o menos fijas; es además un intento humano de "iluminar" el mundo, de dar sentido al mundo. Existencia y mundo no pueden ser separados. La existencia humana se 
realiza a si misma, y lo hace dando forma al mismo tiempo a sí mismo y al mundo. El mundo es transformado de esta manera en un ámbito significativo. Las cosas reciben sentidos, significaciones, y estas significaciones hacen que tanto el mundo como la existencia queden más o menos fijados, encauzados, se impregnen de una cierta densidad material. La posibilidad que el hombre tiene de actuar es a la vez actualizada y encauzada. El niño recién nacido es integrado en un ámbito de existencia preexistente y encauzado, en el cual el significado de las cosas ya está ampliamente fijado. El mundo con el cual nos familiarizamos es el mundo humanizado y previamente encauzado. A este mundo encauzado lo tenemos por tan obvio que nos inclinamos a considerarlo como el mundo natural. Sin embargo, no es el mundo natural sino el mundo constituído por el hombre en el curso de una larga historia común. La facticidad humana, pues, posee un carácter cósico; no obstante, no puede ser considerada absolutamente como una cosa. Puesto que en ella están presentes intenciones humanas, su estructura sólo puede ser comprendida a la luz de esas intenciones. Por esta razón no corresponde aplicar sin ciertas restricciones, como decíamos, el método de las ciencias físicas al estudio de la facticidad humana. Si bien la facticidad humana, objeto de las ciencias humanas, se asemeja a los hechos estudiados por las ciencias físicas, existe no obstante una diferencia esencial. La facticidad es siempre una solidificación de la vida intencional del hombre, y debe ser estudiada como tal. La facticidad humana depende de la existencia instauradora de sentido; de aquí su contingencia esencial, que no halla cabida dentro del objeto propio de las ciencias físicas. Por eso, quien aborde la facticidad humana únicamente como un orden de hechos dados, desestimando la intención que está presente y activa en estos hechos y que los constituye desde dentro, no logrará comprender la naturaleza íntima de los hechos que estudia.

La contingencia esencial propia de la facticidad humana tiene por fundamento la libertad. El dominio de la existencia humana es el dominio de la libertad. Sin embargo, el descubrimiento de la facticidad ha mostrado que existe también necesidad en este dominio de la libertad. En nuestros intentos de expresarnos a nosotros mismos cobramos conciencia de la libertad de que goza nuestro espíritu. Pero 
en esta libertad podemos también descubrir una necesidad. Quien escribe un libro, por ejemplo, expresa libremente sus ideas, pero tiene que hacerlo en un determinado lenguaje y en una determinada época. Lenguaje y época encarnan una cierta manera de pensar de la que el autor no puede escapar. Asf, resulta imposible tratar de deslindar las zonas de la necesidad y de la libertad. Libertad y necesidad se interpenetran. Hasta podría decirse que el hombre es libre gracias a su necesidad. Hay necesidad en su facticidad, pero precisamente es esta facticidad la que le permite obrar libremente. Una persona que no se haya apropiado ningún lenguaje está imposiblitada de expresar el mundo mediante la palabra. Nuestra facticidad nos hace libres para actuar. Y en la medida en que aumenta esta facticidad, poseemos más libertad de movimientos. Entre las tribus primitivas hay muy poca facticidad soçial y por ende, correlativamente, también poca libertad. La facticidad signa nuestra libertad, pero también hace posible la acción libre del hombre. Libertad y necesidad no son, pues, conceptos incompatibles como se pensó regularmente. El error del determinismo social consiste en que habiendo descubierto la necesidad en el dominio de la existencia humana, concluye en la negación de la libertad. Sin embargo, la necesidad en cuestión no niega la libertad sino que más bien la exige. Volviendo al ejemplo del lenguaje: el lenguaje tiene muchas estructuras necesarias y sin tales estructuras un lenguaje no es concebible. Así, en inglés, francés, alemán y castellano solamente conectando un sujeto con un predicado puedo expresar algo. Sin embargo, el lenguaje es también una búsqueda de sentido, un libre movimiento del espíritu, y esto sólo es posible gracias a las estructuras necesarias que el lenguaje nos brinda. Reconocer, pues, la facticidad con la necesidad que le es inherente, no nos autoriza a negar la libertad. La facticidad hace posible la acción libre, proveyendo cauces para tal acción. Es cierto que hay formas de facticidad que impiden la libertad. Una manera de hablar comúnmente admitida puede convertirse en un obstáculo para la genuina visión de las cosas. Las pautas aceptadas de comportamiento pueden llegar a ser tan restrictivas que priven al hombre de la libertad de movimientos. En estos casos la facticidad no desempeña ya el papel que debiera desempeñar. Ya no constituye una estructura que le brinda al hombre posibilidades de realizarse, sino una limitación que lo priva de 
posibilidades. La facticidad se convierte ası́ en un obstáculo para la libertad.

La tesis de que hay necesidad en la existencia humana es el tema fundamental del marxismo. En su estudio de la vida económica Marx descubrió pautas necesarias. Dedicó mucha atención a la vida económica porque pensaba que esta dimensión de la vida humana ejercía una influencia decisiva sobre todas las demás. Marx sostenía que la comprensión de la dimensión económica haría posible comprender la totalidad de la vida. Y si hay necesidad en el desarrollo de la vida económica, esta necesidad penetra todo el desarrollo de la vida del hombre. Ahora bien, ipodemos decir que Marx fué tan lejos como para negar la libertad?. Esta pregunta es diff́cil de contestar. Las obras de Marx muestran una curiosa vacilación. Al parecer, Marx no comprendió con suficiente claridad que la necesidad de que hablaba era una necesidad en la libertad. Se puede decir que Marx estaba luchando ya con un problema que todavía continúa desafiando a las ciencias humanas: el problema de saber cuál es el carácter de la necesidad que se revela en el ámbito de la existencia humana. El marxismo ortodoxo contemporáneo considera generalmente la necesidad presente en la existencia humana como una necesidad de naturaleza, y por consiguiente no deja lugar para la libertad. El mérito del marxismo es haber destacado la importancia del estudio de la facticidad social para lograr una adecuada y correcta comprensión de la vida humana. El marxismo, sin embargo, constituye una doctrina unilateral; primero, porque tiene tendencia a reducir todos los tipos de facticidad a la facticidad económica, y segundo, porque no distingue suficientemente la necesidad "sui generis" de la facticidad humana, que no es una necesidad de naturaleza sino una necesidad en libertad (Sartre). La facticidad social está impregnada íntimamente de intenciones humanas. Por esta razón existe en la facticidad social no sólo necesidad sino también contingencia. Si bien la facticidad social presenta pautas más o menos fijas, lo mismo deja lugar para la iniciativa humana, para la libertad humana. Esta libertad es la que permite darle a la facticiad social un nuevo futuro.

La situación de la facticidad social ha cambiado en cierto sentido en los tiempos actuales. El hombre ha descubierto la facticidad social como una realidad en su vida, y ha fijado deliberadamente su atención 
sobre ella. El hombre ha sacado a la facticidad social de la semioscuridad en que se encontraba, a través del estudio llevado a cabo por las distintas ciencias sociales. Y a través de la investigación cientifica el hombre ha adquirido más poder sobre la facticidad. La tecnología es el prototipo de este nuevo poder. El hombre vive en un mundo utilizable, pero él mismo tiene que planificar este mundo utilizable. Con la tecnología moderna el hombre arroja una luz científica en su tarea de hacer utilizable el mundo. En el campo de la economía también ha habido un aumento de planeamiento, en base al mejor conocimiento de las leyes que gobiernan la vida económica. También aquí se da, aunque todavía limitado, un poder real sobre la facticidad. Y lo mismo ocurre en otros ámbitos de la vida humana. En los tiempos actuales, entonces, la relación entre el hombre y la facticidad social ha cambiado. El hombre ha hecho de su facticidad un objeto de reflexión cientifica, y por medio de esta reflexión puede ahora intervenir de una manera nueva en su facticidad. Y debido a esta posibilidad de intervenir, la facticidad se desarrolla ahora en forma más rápida que en otros tiempos. Este nuevo dinamismo que manifiesta la facticidad social, en razón de la mayor intervención del hombre en dicha facticidad es otro factor que también contradice las pretensiones del determinismo social. Todo indica que el hombre no está enteramente sujeto a su facticidad. Es verdad que está influido por ella, dado que hace posible su existencia y lo sostiene en todo lo que hace. No obstante, la facticidad no es un poder ciego que fuerce irremisiblemente su existencia en una dirección determinada. El hombre es capaz de reflexionar y, mediante su libertad, de influir sobre las fuerzas que hacen posible su propia existencia. La facticidad influye sobre el hombre, pero también el hombre ejerce influencia sobre la facticidad. La libertad humana es portadora de facticidad, pero también la facticidad es portadora de libertad. Las ciencia sociales, al estudiar científicamente la facticidad humana, brindan hoy un sustancial aporte para un desarrollo más racional y más armonioso de la sociedad humana. Las ciencias sociales demuestran el poder del espíritu humano, el poder de la libertad. No deja de resultar extraño, por tanto, que algunos cultores de las ciencias sociales se inclinen por el sociologismo o determinismo social. 


\section{La persona y la facticiad social}

Si bien la persona depende de la facticidad social, esta misma facticidad accede a la existencia solamente en la persona. Las pautas de comportamiento sólo existen en tanto que los hombres actúan conforme a esas pautas. Un lenguaje existe realmente sólo porque es hablado por el hombre. La ciencia existe solamente en tanto hay hombres que saben. La facticidad social hace que existan los seres humanos, pero ella misma accede a la existencia en esos seres. En otros términos, la facticidad social no tiene existencia autónoma.

Ahora bien, la afirmación de que la facticidad social aflora a la existencia real en la persona. no implica que esta facticidad sea asumida en todos sus aspectos de una manera consciente y libre. La facticidad social es incorporada a la vida de la persona en todos los niveles de su existencia y no solamente en el de la elección deliberada. Lo que significa que en nuestra existencia aceptamos y asumimos muchas cosas sin someterlas a un análisis crítico. La reflexión total, por otra parte, es imposible. Si tuviéramos que reflexionar críticamente sobre todas las pautas de conducta, todas las maneras de hablar, todas las concepciones y todos los modos de proceder, jamás estariamos en condiciones de hacer nada. La facticidad social debe posibilitar una existencia humana con sentido, pero este sentido puede ser asumido de una manera personal sin una previa reflexión teórica sobre él. El hombre normalmente se decide a reflexionar sobre el sentido cuando el sentido asumido ya no le satisface, o sea que muchas veces esta reflexión se impone por la vía del descontento existencial. Lo cual significa que la facticidad social ha perdido vigencia y por lo tanto debe ser modificada. El descontento que manifiesta el hombre de nuestra época y sus constantes reflexiones sobre el sentido de la facticidad presente, demuestra que esta facticidad ha entrado en crisis y debe ser transformada.

La función de la facticidad social es hacer que la persona exista de una manera con sentido. La persona no se realiza a si misma por su propio poder, sino dentro de la coexistencia con sus semejantes, en la interacción con la facticidad social. La facticidad social debe siempre ofrecer a la persona la posibilidad de desarrollar sus capacidades, debe invitarla al autodesarrollo. Desgraciadamente, como ya lo dijéramos, 
la facticidad social no siempre cumple su finalidad. Hay muchisimas formas de facticidad social que restringen y obstruyen la existencia de la persona, en lugar de desarrollarla. La facticidad política, la socioeconómica, la cultural, pueden tanto favorecer como limitar las posibilidades de realización humana. Cuando la facticidad social no promueve el desarrollo de todas las personas, sino que favorece a unos pocos a expensas de grandes grupos, en este caso existe una opresión estructural o una violencia estructural. Los grandes grupos humanos están imposibilitados de una vida digna, no por la violencia de las personas individuales, sino por las estructuras establecidas de la vida misma. La facticidad social, por tanto, debe ser organizada de tal manera que el mundo humanizado y confortable se vuelva, tanto cuanto sea posible, accesible a todos. La existencia de esta posibilidad es quizás uno de los rasgos más felices de nuestra era. Al presente, en efecto, el poder del hombre sobre el mundo ha llegado a ser tan grande merced al desarrollo de la ciencia y la tecnología, que en principio se ha vuelto ahora posible hacer accesible a todos el mundo humanizado. Esta posibilidad ha dado nacimiento a una nueva actitud frente a la facticidad social. El hombre quiere ahora que la facticidad social haga posible a todos los seres humanos el llevar una existencia digna del hombre, no sólo desde el punto de vista material sino también social y cultural. No admite ya más que algunos grupos sean puestos fuera de la frontera del mundo humanizado y confortable.

La facticidad social debe ofrecer a la persona la oportunidad de realizarse en todos los niveles de su existencia. En todos los niveles hay interacción, pues no sólo está activa la facticidad social sino que también lo está la persona, porque ésta tiene que asumir la facticiad y hacerla suya. La facticidad social tiene el carácter de una invitación y como tal necesita ser aceptada por la persona. La interacción entre la persona y la facticidad social, no obstante, varía según los diversos niveles de existencia. Con relación a ciertas pautas de comportamiento social, como la manera de vestirse, de alimentarse, de dirigirse a los demás, de expresarse, etc., la facticidad social tiene un carácter casi compulsivo. En la esfera de la vida cientifica y artística, en cambio, la facticidad social es menos compulsiva. Aquí es mucho más una invitación que solicita una decisión y una participación personal. Sería de suma 
importancia determinar los diferentes niveles de la facticidad social e investigar qué forma asume la interacción entre la facticidad social y la persona en cada uno de esos niveles. Tal investigación tendría también un valor pedagógico, pues las diferentes formas de facticidad social tienen que ser comunicadas a través de la educación, pero cada una de ellas según la manera que le es propia y con la cantidad adecuada de presión. Sería erróneo impartir una forma de facticiad social de una manera que no se adecúa a su carácter.

Toda la función de la facticidad social consiste en hacer que la persona sea. Ahora bien, el análisis de la facticidad social nos ha mostrado que debemos asumir una actitud crítica frente a nuestra facticidad. Sin esa actitud crítica no hay progreso posible. Encontramos aquí otra razón por la cual la facticidad social necesita de la persona, puesto que la crítica es una actividad que sólo puede ejercerela una persona. El término "crítica" deriva del verbo griego "krinein" (separar). La crítica separa lo que tiene sentido de lo que no lo tiene, el valor del no-valor. Esta separación se efectúa especialmente a través del juicio, que es donde la crítica alcanza su forma más clara de expresión. La crítica la ejerce la persona que ve y que juzga. No existe una visión colectiva ni un juicio colectivo. Hay, por supuesto, juicios que todos repiten en forma de "slogans", pero en alguna ocasión fueron dichos por primera vez por una persona individual. La crítica es personal porque la comprensión y el juicio son actos personales.

La facticidad social necesita de la crítica para desarrollarse favorablemente, o sea que necesita de la persona para poder progresar. La facticidad social no se desarrolla como un proceso natural porque el progreso humano no es un proceso mecánico. El progreso surge de los esfuerzos de las personas humanas que comprenden la situación y expresan sus concepciones. La facticidad social se beneficia con el agudizamiento de la capacidad crítica de las personas. De aquí que una sociedad sigue una política de muy cortas miras cuando trata de suprimir la crítica por parte de sus miembros. En el mundo moderno la crítica ocupa un lugar extremadamente importante, no la crítica irresponsable sino la que ha alcanzado el nivel científico. Pocas cosas emprende el hombre moderno sin recurrir a la crítica científica. Esta es una de las 
razones por las cuales el desarrollo progresivo de la facticidad social se efectua ahora de un modo tan acelerado. La facticidad social, como dijimos, no tienen otra función que la de hacer que existan como personas los seres humanos. Sin embargo, esta facticiad es asumida de una manera responsable sólo cuando se la asume críticamente. Estrictamente hablando, no es humano asumir algunos elementos de la facticidad social sin juzgar que son valiosos.

La existencia personal es el sentido de la facticidad social. Quizá sea necesario aclarar que "personal" no es igual a "independiente". La tendencia a establecer esta equiparación surge del hecho de que la persona es concebida como una fuente absoluta, una fuente que rechaza toda forma de dependencia. En este caso, la dependencia de la facticidad social implicaría la negación de una existencia auténticamente personal. Sin embargo, como hemos visto, esta concepción no se adecúa a la realidad de la persona humana. El hombre es realmente fuente y origen, porque él mismo es el que piensa, decide y obra. El puede responder por estas actividades. Al mismo tiempo, sin embargo, y por paradojico que pueda parecer, la persona humana tiene que ser ayudada para ser capaz de ser fuente y origen. La dependencia de la facticidad es inevitable. Por esta razón, dependencia y personalidad no están en razón inversa, sino directa. Crecen y se desarrollan juntas. En nuestra época, la facticidad social y por consiguiente la dependencia son mucho mayores y más ricas que en las edades primitivas de la humanidad. Pero, al mismo tiempo, la existencia del hombre es mucho más libre y personal que durante aquella fase primitiva de la historia de la humanidad. El hombre mismo es, pero tiene que ser ayudado para ser capaz de ser él mismo. Cuanto más se nos ayuda, en mejores condiciones estamos de llevar una existencia personal.

\section{Persona, facticidad social y educación}

El análisis de la dimensión social de la existencia que hemos efectuado permite que se obtengan algunas consecuencias importantes para la educación.

1. Si la función de la facticidad social es hacer que la persona sea, si la persona es el sentido de la facticidad social, la educación, que es 
la encargada de transmitir la facticidad, debe hacerlo de tal modo y con tales medios que contribuya eficazmente al proceso de personalización.

2. Si la socialidad es constitutiva de la existencia humana, la socialización o proceso de asimilación de las pautas sociales pasa a ser una condición ineludible del proceso de personalización. Si la libertad de la persona y la necesidad de la facticidad social no son aspectos incompatibles; más aún, son aspectos que se requieren e implican mutuamente, la socialización no sólo no atenta sino que constituye una parte fundamental de la realización propia de la naturaleza humana. Solamente para las posiciones individualistas, o sea, para quienes equiparan "personal" con "indipendiente" la socialización puede significar un peligro para el desarrollo de la autonomía personal. La sociedad es una parte esencial del hombre; luego, asumir la facticidad social es la única forma de alcanzar la plena autonomía. Educar es personalizar, pero par ello es necesario previamente socializar. La socialización, sin embargo, no debe interpretarse como un proceso de mera adaptación del individuo a la facticidad social, como ocurre en las concepciones pedagógicas de base sociologista. Ya Durkheim sostenía que la educación es la "acción ejercida por las generaciones adultas sobre las generaciones jóvenes para adaptarlas a su medio social y físico". Hoy, desde posiciones doctrinarias distintas, se insiste en sostener planteos similares. La socialización no consiste en un proceso de mera adaptación a la realidad social. Fundamentalmente debe plantearse como una necesidad propia del desarrollo de la persona que, si encuentra patrones y modelos en la facticidad social, los asume, no pasiva sino activamente, en la perspectiva del cambio y la innovación. Sólo quien asume con mentalidad creadora la sociedad tiene posiblidad de transformarla y mejorarla.

3. La vida humana está sostenida por la facticidad social; por eso todo grupo social tiende a transmitir su facticidad a la posteridad. Como consecuencia de esta tendencia, la acción educativa se ha tornado cada vez más compleja a medida que la riqueza de la tradición ha ido creciendo en variedad y profundidad. Deben hacerse esfuerzos, no obstante, para impedir que la facticidad social sea tan forzosamente impuesta a la generación más joven, que esos jóvenes sean incapaces de 
situarse a distancia de esa facticidad y, de acuerdo con su grado de madurez, llegar a evaluarla con independencia. Dos errores se pueden cometer en esta materia. En primer lugar, el joven puede quedar librado a sus propios recursos en una medida tal que no reciba la facticidad social suficiente como para poder adoptar una posición fundada, crítica y personal. En segundo lugar, también es erróneo imponer la facticidad social de una manera tan forzada que en la práctica no quede lugar para una elección personal. La educación debe habilitar no solamente para participar de la facticidad social existente, sino también para asumir una actitud crítica y personal con respecto a ella.

4. Es cierto que la facticidad social contiene formas y estructuras de coacción, de domesticación, y es verdad también que la tentación manipuladora está muy a menudo presente en los procesos educativos. Pero ésta es la realidad y éste es el desafío y la lucha que hay que enfrentar, lucha que en gran medida debe partir de la escuela: "Quien ha realizado el aprendizaje de la libertad tiene mayores posibilidades de luchar contra todas las formas de dominación, de autoritarismo y de compulsión" (Bruera). La alienación no depende tanto de factores externos como de la falta de capacidad de respuesta del hombre frente a las condiciones enajenantes de la facticidad. El sentido más profundo de la educación radica en la conquista de la autonomía, en la asunción de la responsabilidad de la propia existencia. La libertad, si bien es un don, también es una tarea, un duro aprendizaje. Por eso nadie puede sustituir el esfuerzo personal en el acto de asumir el propio desarrollo. El adoctrinamiento, los paternalismos, las compulsiones de las tecnologías de la conducta constituyen en sI mismos negaciones de la esencia de un proceso educativo auténtico. El verdadero educador hace ser a la persona educada, pero este hacer-ser implica precisamente que el otro es llevado a ser autónomo, a ser él mismo, a pensar por sí mismo, a valorar por sí mismo; en suma, a existir realmente como persona. Si bien estos principios fundamentan comúnmente las teorfas pedagógicas, lo que no es habitual es que las instrumentaciones didácticas de tales teorías se correspondan con dichos principios. ¿Cuántos profesores que se autodefinen como "personalistas" no utilizan didácticamente las técnicas reproductoras y manipuladoras del conductismo?. No se puede confundir el aprendizaje humano con los condicionamientos de la 
conducta animal, que reduce el aprendizaje a automatismos y comportamientos reflejos. Si el aprendizaje es realmente "humano", no puede desconectarse entonces de lo que el hombre es por naturaleza, o sea, ser autoconsciente y libre.

5. Educar es una función amplia que compete a la socieda entera. La enseñanza formal, en cambio, que es una función más restringida, corresponde a la escuela. La escuela es un agente básico del proceso educativo, pero pretender que asuma la total responsabilidad de una educación integral es como confundir la parte con el todo. La función específica de la escuela es, como dice Gozzer, dar instrumentos: instrumentos de conocimiento, instrumentos de habilidades, instrumentos de reflexión y de crítica. Y del mismo modo que no corresponde al médico establecer el uso que hará el paciente de su salud recuperada, así tampoco corresponde al docente establecer cómo su alumno usarálos instrumentos que él le ha proporcionado. "El desafío profesional de la escuela, dice el mismo autor, es todavía un desafío de libertad".

\section{BIBLIOGRAFIA}

Luypen W., Fenomenología existencial. Lohle, Buenos Aires.

Fenomenología del derecho natural. Lohlé, Buenos aires.

Kwant R.., Filosofía social. Lohlé, Buenos Aires.

La filosofía de Carlos Marx. Lohlé, Buenos Aires

Lersch Ph., Psicología social - El hombre como ser social. Scientia, Barcelona.

Mounier E. El personalismo. Eudeba, Buenos Aires.

Bruera R.., La matética. Matética S.A., Rosario.

Coloquios con Gozzer., Bajo el cuidado de R. Bruera. COASCE, Rosario.

García Hoz V., Educación personalizada. Rialp, Madrid. 


\section{RESUMEN}

1. El redescubrimiento del carácter social de la existencia humana constituye uno de los rasgos fundamentales de nuestra época. El hombre es un ser social en todo. Esto no excluye, sin embargo, la dimensión personal, autónoma de la existencia.

2. La acentuación de la socialidad constitutiva del hombre condujo a la ideolgía del determinismo social o sociologismo. El hombre es visto sólo como un producto o resultado de las estructuras y procesos sociales. La independencia y la libertad del hombre son ilusiones. Si bien nuestra existencia implica una relación de dependencia respecto de nuestros semejantes, esta relación no es de carácter determinista. Esto se hace evidente a través del análisis del concepto fenomenologico de "facticidad".

3. La facticidad designa la clase típicamente humana de hechos que condicionan la existencia del hombre. La facticidad social presenta un carácter cósico, pero en ella está siempre presente la intencionalidad de la existencia; de ahr su contingencia esencial. La necesidad de la facticidad no es una necesidad de naturaleza sino una "necesidad en libertad".

4. La función de la facticidad social es hacer que la persona se autodesarrolle y realice en plenitud sus posibilidades. Existen muchas formas de facticidad social que restringen y obstruyen la existencia de la persona, en lugar de desarrollarla. Debemos asumir una actitud crítica frente a nuestra facticidad. Sin esa actitud crítica no hay progreso posible. La facticidad social necesita de la persona para poder progresar y crear mejores condiciones para todos.

5. Si la persona es el sentido de la facticidad social, la educación, como encargada de trasmitir la facticidad, debe contribuir eficazmente al proceso de personalización. La sociedad es una parte esencial del hombre; luego, asumir la facticidad social es una forma de alcanzar la plena autonomía. Educar es personalizar, pero para ello es necesario previamente socializar. La socialización, sin embargo, no debe entenderse como mera adaptación, sino como un proceso donde los modelos 
y patrones de la facticidad social son asumidos no pasiva sino activamente, en la perspectiva del cambio y la innovación. Sólo quien asume con mentalidad creadora a la sociedad tiene posibilidad de transformarla y mejorarla. 